\title{
Vitamin D receptor genotypes and their association with the 5-year changes in bone mineral density in Spanish postmenopausal women.
}

Moran JM, Pedrera-Canal M, Lavado-Garcia JM, Roncero-Martin R, Rey-Sanchez P, Calderon-Garcia JF Pedrera-Zamorano JD Metabolic Bone Diseases Research Group, University of Extremadura, Cáceres, Spain.

\section{OBJECTIVES}

\section{METHODS}

Our aims were to follow the longitudinal changes after $5-y r$ in femoral neck (FN), femoral trochanter (FT), L2, L3, L4 and L2-L4 bone mineral density (BMD) in Spanish postmenopausal women and to study whether the polymorphism Bsml in the vitamin D receptor (VDR) may influence these results.
We conducted a 5-yr prospective study of BMD and its change in 174 women, aged 43-78 yr. BMD was measured by densitometry. Genotypes were analyzed by Real Time PCR with Taqman $₫$ probes. The women were members of the Caceres Reference Database for the Diagnosis of Osteoporosis (CAFOR), a population-based longitudinal study of BMD. Changes were analysed by Wilcoxon test. We also examined the effect of adjustments for dietary and anthropometric factors on these associations.
Table 1. BMD evolution accross the study period

\begin{tabular}{|c|c|c|c|}
\hline & Mean & $\pm S D$ & P-value \\
\hline Baseline BMD FN ( $\left.\mathrm{gr} / \mathrm{cm}^{2}\right)$ & 0,709 & 0,095 & \multirow{2}{*}{$<0.001$} \\
\hline Final BMD FN $\left(\mathrm{gr} / \mathrm{cm}^{2}\right)$ & 0,698 & 0,099 & \\
\hline Baseline BMD FT ( $\left.\mathrm{gr} / \mathrm{cm}^{2}\right)$ & 0,553 & 0,087 & \multirow{2}{*}{$<0.001$} \\
\hline Final BMD FT ( $\left.\mathrm{gr} / \mathrm{cm}^{2}\right)$ & 0,578 & 0,086 & \\
\hline Baseline BMD L2 $\left(\mathrm{gr} / \mathrm{cm}^{2}\right)$ & 0,748 & 0,085 & \multirow{2}{*}{0.598} \\
\hline Final BMD L2 ( $\left.\mathrm{gr} / \mathrm{cm}^{2}\right)$ & 0,753 & 0,098 & \\
\hline Baseline BMD L3 $\left(\mathrm{gr} / \mathrm{cm}^{2}\right)$ & 0,754 & 0,077 & \multirow{2}{*}{$<0.001$} \\
\hline Final BMD L3 $\left(\mathrm{gr} / \mathrm{cm}^{2}\right)$ & 0,770 & 0,096 & \\
\hline Baseline BMD L4 ( $\left.\mathrm{gr} / \mathrm{cm}^{2}\right)$ & 0,722 & 0,078 & \multirow{2}{*}{$<0.001$} \\
\hline Final BMD L4 ( $\left.\mathrm{gr} / \mathrm{cm}^{2}\right)$ & 0,757 & 0,098 & \\
\hline Baseline BMD L2-L4 $\left(\mathrm{gr} / \mathrm{cm}^{2}\right)$ & 0,740 & 0,071 & \multirow{2}{*}{$<0.001$} \\
\hline Final BMD L2-L4 ( $\left.\mathrm{gr} / \mathrm{cm}^{2}\right)$ & 0,760 & 0,088 & \\
\hline
\end{tabular}

Table 2. Mean intake of nutrients accross the study period between studied groups.

\begin{tabular}{|c|c|c|c|c|c|c|c|}
\hline & \multicolumn{2}{|c|}{$\mathrm{bb}$} & \multicolumn{2}{|c|}{$\mathrm{Bb}$} & \multicolumn{2}{|c|}{ BB } & \multirow[b]{2}{*}{ P-value } \\
\hline & Mean & SD & Mean & SD & Mean & SD & \\
\hline Intake of Vitamin D(ug/day) & 14,15 & 23,49 & 15,87 & 43,54 & 7,02 & 4,85 & 0,01 \\
\hline Intake of $\mathrm{Ca}(\mathrm{mg} /$ day) & 1220,33 & 472,43 & 1219,73 & 555,63 & 1120,39 & 456,23 & 0,62 \\
\hline Intake of Kcal (Kcal/day) & 2318,96 & 764,19 & 2257,18 & 686,18 & 2273,02 & 653,37 & 0,71 \\
\hline
\end{tabular}

Table 3. Anthropometric factors accross the study period between studied groups.

\begin{tabular}{l|rr|rr|rrr} 
& \multicolumn{2}{c}{ bb } & \multicolumn{2}{c}{ Bb } & \multicolumn{2}{c}{ BB } & \\
\cline { 2 - 7 } & \multicolumn{1}{c|}{ Mean } & \multicolumn{1}{c}{ SD } & \multicolumn{1}{c}{ Mean } & \multicolumn{1}{c}{ SD } & Mean & \multicolumn{1}{l}{ SD } & P-value \\
Weigth (Kg) & 63,05 & 11,18 & 62,71 & 11,44 & 62,41 & 9,16 & 0,68 \\
Heigth (m) & 1,53 & 0,06 & 1,53 & 0,06 & 1,52 & 0,09 & 0,72 \\
BMI (Kg/m2) & 26,93 & 5,15 & 26,77 & 4,82 & 27,49 & 6,09 & 0,87
\end{tabular}

\section{RESULTS}

After the 5-yr period significant changes were observed in L3, L4, L2-L4, FN and FT ( $<<0.001$ in all cases). No significant changes were observed in $L 2(P=0.598)$.

Before adjustments, in women homozygous for the $b$ allele (genotype $(b b) n=25)$ no significant changes were observed $(P>0.05$ in all cases). Women heterozygous (genotype $(B b) n=73)$ had less FT BMD $(P<0.001)$, L4 $(P<0.001)$ and $L 2-L 4$ $(P=0.010)$ over time; no changes were observed over the 5 -yr period in $B b$ women in FN, L2 and L3 BMD. In women homozygous for the $B$ allele $(n=76)$ significant loss in BMD was observed in $F N(P=0.010)$ and $F T(P<0.001) B M D$ as well as in L4 $(P<0.001)$ and L2-L4 $(P=0.012) B M D$ after the 5-yr period. No changes were observed in L2 and L3 BMD ( $P>0.05$ in both cases). Upon adjustment for dietary and anthropometric factors no further statistically significant associations to Bsml polymorphism were found.

\section{CONCLUSIONS}

Our results reveal that to correctly address the association between bone loss and VDR polymorphism Bsml in small samples, it is necessary to consider the variations in dietary and anthropometric factors.

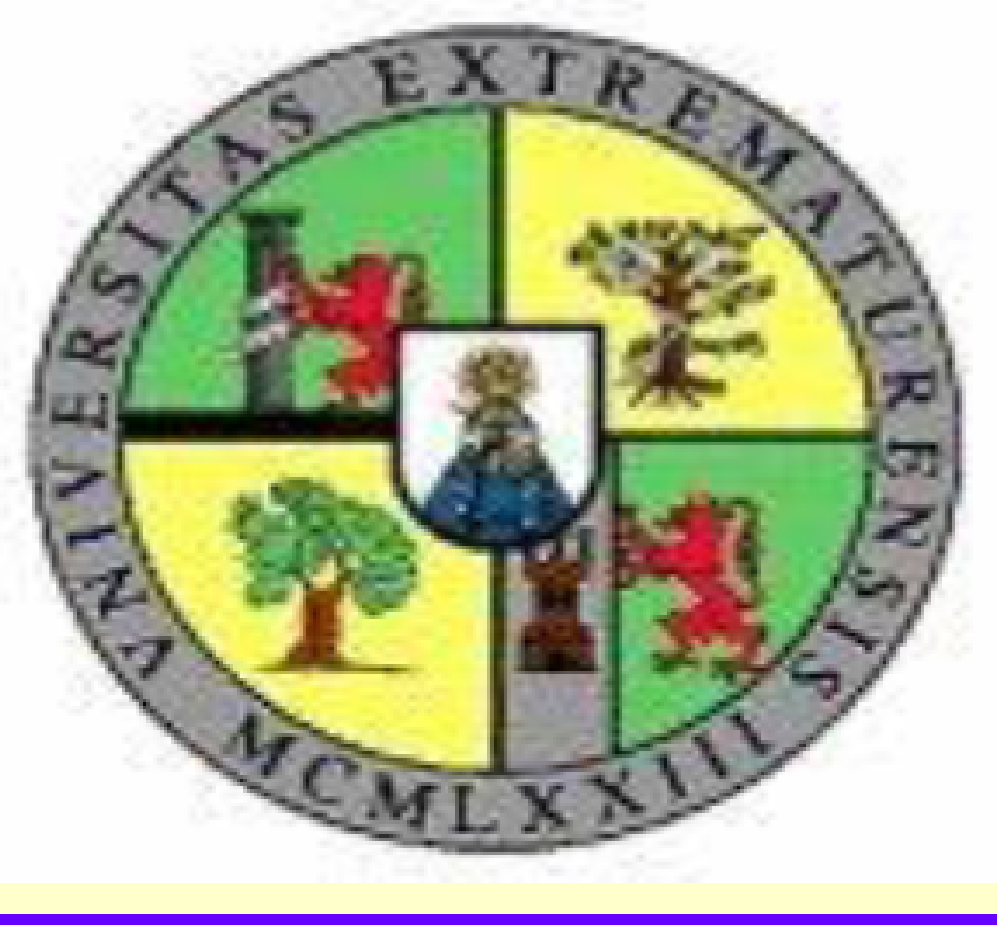

